\title{
Medical malpractice and meningiomas: an analysis of 47 cases
}

\author{
Andre E. Boyke, MS, ${ }^{1}$ Edward R. Bader, MBChB, ${ }^{2}$ Ishan Naidu, BSE, BBA, ${ }^{1}$ Sharon Lam, BS, ${ }^{1}$ \\ Mohammed Ali Alvi, MBBS, MS, ${ }^{3}$ Abigail Funari, BS, ${ }^{1}$ and Vijay Agarwal, MD ${ }^{1,2}$
}

1Department of Neurological Surgery, Montefiore Medical Center, New York; ${ }^{2}$ Department of Neurological Surgery, Albert Einstein College of Medicine, New York, New York; and ${ }^{3}$ Department of Neurological Surgery, Mayo Clinic, Rochester, Minnesota

\begin{abstract}
OBJECTIVE Among medical practices, surgical fields, including neurosurgery, are at a high risk for medical malpractice litigation. With meningiomas contributing to $10 \%$ of the total neurosurgery litigation cases, the aim of this study was to identify demographic characteristics, reasons for litigation, and surgical complications commonly reported in these cases. This analysis serves to increase neurosurgeons' awareness of factors associated with medical malpractice litigation. METHODS The online legal database Westlaw was utilized to query public litigation cases related to the medical management of meningiomas between December 1985 and May 2020. Variables extracted included the following: plaintiff and defendant demographics, litigation category, plaintiff medical complaints, and trial outcomes. The authors compared these characteristics between cases with decisions in favor of the defendant and those with decisions in favor of the plaintiff.
\end{abstract}

RESULTS A total of 47 cases met the inclusion criteria. Failure to diagnose (68.1\%) was the most common type of malpractice claim, and surgical complications (19.1\%), motor weakness (33\%), and financial loss (33\%) were cited as the most common postoperative complaints. Individual specialties that most often required defense due to malpractice claims were radiology (21.7\%) and neurosurgery (19.6\%). The jury verdict was in favor of the defense in $51.1 \%$ of cases and in favor of the plaintiff in $27.7 \%$ of cases. A settlement was reached in $19.1 \%$ of cases. The mean payout for a verdict in favor of the plaintiff was $\$ 3,409,650.22$, while the mean payout for settlements was $\$ 867,555.56$. The greatest average payout for specialties was in neurosurgery at $\$ 3,414,400$, followed by radiology at $\$ 3,192,960$. Cases with a verdict in favor of the plaintiff were more likely to involve an internal medicine physician as a defendant $(p=0.007)$.

CONCLUSIONS Over one-half of the cases resulted in a defendant's verdict with failure to diagnose cited as the most common reason for litigation. Radiology and neurosurgery were the most common specialties for legal cases and also had some of the largest average payouts based on specialty. Motor weakness and financial loss were the most common plaintiff postoperative complaints. These findings may inform surgeons on active measures to take, such as increasing focus on diagnostic accuracy and reducing specific postoperative complaints, such as motor weakness, through risk management and prophylactic measures, to reduce unfavorable legal outcomes.

https://thejns.org/doi/abs/10.3171/2020.8.FOCUS20598

KEYWORDS meningioma; medicolegal; medical malpractice; neurosurgery

$\mathrm{S}$ URGICAL fields, including neurosurgery, are medical specialties at a high risk for medical malpractice litigation. ${ }^{1}$ It has been shown that malpractice lawsuits are strongly associated with physician depression, burnout, and suicidal ideation. ${ }^{2}$ In addition to jeopardizing the health of physicians, burnout is a major cause of medical errors. ${ }^{3}$ Patients suffering from preventable medical complications due to such errors may pursue legal action, creating a vicious cycle of medical malpractice litigation that is estimated to cost $\$ 55.6$ billion annually. ${ }^{4}$
Fearing potential litigation, physicians have reported using more positive assurance behaviors to deter patients from filing lawsuits, such as ordering unnecessary clinical examinations and consultations. ${ }^{5}$ These actions contribute to a shift toward defensive medicine, a practice whereby physicians feel the need to protect themselves in a way that does not act in the best interest of the patient. ${ }^{6}$ Therefore, it is essential to investigate reasons for litigation in neurosurgery to minimize defensive medicine practices and protect the interests of both physicians and patients. Inter- 
estingly, it has been recently found that the probability of litigation in neurosurgery cases is more strongly associated with the type of cases rather than the complexity of the cases. ${ }^{7}$ In a 31-year review of malpractice litigation associated with brain tumor surgeries, meningioma was one of the most commonly cited diagnoses, contributing to $10 \%$ of the total litigation cases. ${ }^{8}$ This high litigation rate may be influenced by the neuroanatomical positioning of meningiomas. In some cases, difficult tumor positions or proximity to critical neurovascular structures does not allow for complete total resections, which leads to increased surgical risks and medical complications. ${ }^{9}$

To our knowledge, malpractice litigation cases that involve patients diagnosed with meningiomas have not been studied in great detail. The aim of this study was to identify demographic characteristics, reasons for litigation, and surgical complications commonly reported in these cases. The information presented serves to increase neurosurgeons' awareness of factors associated with medical malpractice litigation before surgically treating a patient with a meningioma. This knowledge can then be utilized to practice good risk management, minimize costly positive assurance behaviors, and improve patients' and physicians' overall well-being.

\section{Methods \\ Data Source}

In this study, the online legal database Westlaw Edge (Thomson Reuters) was utilized to query public litigation cases related to the management of meningiomas (Westlaw-Online Legal Research). Westlaw is one of the two largest legal databases, with more than 40,000 databases of statutes, public records, and case laws from both the United States federal court and the state and local courts (data from Westlaw-Online Legal Research). This data source is routinely used for reviewing court records and case descriptions across all states. ${ }^{10}$ Cases submitted to Westlaw are screened and edited by attorneys to ensure accuracy. Cases may include those that are added voluntarily by attorneys as well as those that are added anonymously or confidentially.

\section{Cohort}

Cases that pertained to the medical diagnosis and management of meningiomas were included in the study. The search criterion "meningioma" was applied, and all federal- and state-level courts were searched for "jury verdicts and settlements" between December 1985 and May 2020. Each case produced by the aforementioned search criteria was read in detail in order to determine eligibility and accuracy. Cases with a largely nonmedical focus or those identified as duplicates were not included in our analysis.

\section{Covariates and Outcomes of Interest}

Data pertinent to meningioma were extracted and recorded. Variables extracted included the following: plaintiff and defendant background, trial year, litigation category, plaintiff medical complaints, trial outcome, and payout if applicable. We also reported demographic character- istics, including patient age and sex. We also compared these characteristics between cases that had a verdict in favor of the defendant (physician) and those cases that had a verdict in favor of the plaintiff.

\section{Statistical Analysis}

Continuous variables were summarized using means and standard deviations and compared between cases in favor of the defendant and cases in favor of the plaintiff using a t-test or Wilcoxon rank-sum test. Categorical variables were summarized using frequencies and proportions and compared between the two groups using chi-square or Fisher exact tests.

\section{Results}

Seventy-three cases relating to meningiomas and medical malpractice occurring from 1987 to 2019 were obtained from the primary search. Due to nonmedical claims, motor vehicle accidents, duplicate files, or insufficient information, 26 cases were excluded from the study. In total, 47 cases were eligible for inclusion in this analysis.

\section{Demographics}

The total 47 cases included $28(60 \%)$ involving female patients, $16(34 \%)$ involving male patients, $1(2 \%)$ case involving both sexes, and 2 (4\%) cases for which the patient sex was not stated (Table 1). Of these, the average age of patients who filed a claim was 55.1 years.

\section{Geographic Distribution}

Legal cases were distributed across 17 states in the United States. California $(\mathrm{n}=12 ; 25.5 \%)$ and New York $(\mathrm{n}=6 ; 12.8 \%)$ presented the greatest number of cases (Table 1). Other states had significantly fewer cases, with the fewest cases being found in Arizona, Colorado, Missouri, Utah, and Wisconsin, each having only 1 (2.1\%) case each.

\section{Reasons for Litigation}

Failure to diagnose ( $\mathrm{n}=32 ; 68.1 \%$ ) was found to be the most common type of malpractice claim (Table 1). Surgical complications $(n=9 ; 19.1 \%)$ and negligent followup care $(n=5 ; 10.6 \%)$ followed in frequency. Remaining malpractice cases included in the study cited failure to treat $(\mathrm{n}=3 ; 6.4 \%)$ and failure of informed consent $(\mathrm{n}=$ $3 ; 6.4 \%)$.

\section{Plaintiff Complaints or Outcomes Involved in Claim}

Concerning preoperative complaints and complaints in those who never underwent a surgical procedure, plaintiffs most frequently complained of headache or chronic headache $(n=9 ; 20 \%)$ or visual impairment or loss $(n=4$; 9\%) (Table 1). Other complaints in this group of patients included seizures, motor weakness, or emotional distress, which each occurred in at least $2(4 \%)$ patients. The most frequent complaints claimed following a surgical procedure were motor weakness and financial loss, each with 15 (33\%) plaintiffs (see Table 1). Visual impairment or 
TABLE 1. Summary of key characteristics

\begin{tabular}{|c|c|}
\hline Variable & Total $(n=47)$ \\
\hline \multicolumn{2}{|l|}{ Demographics } \\
\hline Patient age in yrs, mean \pm SD & $55.1 \pm 13.7$ \\
\hline No. $(\%)$ of females & $28(60 \%)$ \\
\hline \multicolumn{2}{|l|}{ Geographic distribution } \\
\hline Arizona & $1(2.13 \%)$ \\
\hline California & $12(25.5 \%)$ \\
\hline Colorado & $1(2.1 \%)$ \\
\hline Florida & $2(4.3 \%)$ \\
\hline Illinois & $3(6.4 \%)$ \\
\hline Indiana & $2(4.3 \%)$ \\
\hline Massachusetts & $3(6.4 \%)$ \\
\hline Michigan & $3(6.4 \%)$ \\
\hline Missouri & $1(2.1 \%)$ \\
\hline New Jersey & $2(4.3 \%)$ \\
\hline New York & $6(12.8 \%)$ \\
\hline Oregon & $2(4.3 \%)$ \\
\hline Pennsylvania & $3(6.4 \%)$ \\
\hline Texas & $2(4.3 \%)$ \\
\hline Utah & $1(2.1 \%)$ \\
\hline Washington & $2(4.3 \%)$ \\
\hline Wisconsin & $1(2.1 \%)$ \\
\hline \multicolumn{2}{|l|}{ Type of court } \\
\hline Circuit & $11(23.4 \%)$ \\
\hline Court of Common Pleas & $3(6.4 \%)$ \\
\hline District & $5(10.6 \%)$ \\
\hline Superior & $18(28.3 \%)$ \\
\hline Supreme & $5(10.6 \%)$ \\
\hline Unknown state court & $1(2.1 \%)$ \\
\hline \multicolumn{2}{|l|}{ Malpractice vs negligence lawsuit } \\
\hline Malpractice & $41(87.2 \%)$ \\
\hline Negligence & $6(12.8 \%)$ \\
\hline \multicolumn{2}{|l|}{ Reasons for litigation* } \\
\hline Failure to diagnose & $32(68.1 \%)$ \\
\hline Surgical complications & $9(19.1 \%)$ \\
\hline Negligent follow-up care & $5(10.6 \%)$ \\
\hline Failure to treat & $3(6.4 \%)$ \\
\hline Failure of informed consent & $3(6.4 \%)$ \\
\hline \multicolumn{2}{|l|}{ Plaintiff complaints } \\
\hline \multicolumn{2}{|c|}{ Preop claims/those who did not undergo surgery } \\
\hline Acute or chronic headache & $9(20 \%)$ \\
\hline Visual impairment or loss & $4(9 \%)$ \\
\hline Seizure & $2(4 \%)$ \\
\hline Motor weakness & $2(4 \%)$ \\
\hline Emotional distress & $2(4 \%)$ \\
\hline \multicolumn{2}{|l|}{ Postop claims } \\
\hline Motor weakness & $15(33 \%)$ \\
\hline Financial loss & $15(33 \%)$ \\
\hline Visual impairment or loss & $12(26 \%)$ \\
\hline Death & $12(26 \%)$ \\
\hline
\end{tabular}

» CONTINUED FROM PREVIOUS COLUMN

TABLE 1. Summary of key characteristics

\begin{tabular}{|c|c|}
\hline Variable & Total $(n=47)$ \\
\hline \multicolumn{2}{|l|}{ Plaintiff complaints (continued) } \\
\hline \multicolumn{2}{|l|}{ Postop claims (continued) } \\
\hline Cranial nerve injury & $8(17 \%)$ \\
\hline Emotional distress & $7(15 \%)$ \\
\hline Stroke & $5(11 \%)$ \\
\hline Speech impairment & $5(11 \%)$ \\
\hline \multicolumn{2}{|l|}{ Specialties of defendants } \\
\hline Hospital & $19(41.3 \%)$ \\
\hline Anesthesiology & $1(2.2 \%)$ \\
\hline Cardiology & $1(2.2 \%)$ \\
\hline Emergency medicine & $1(2.2 \%)$ \\
\hline Endocrinology & $1(2.2 \%)$ \\
\hline Family practice & $2(4.3 \%)$ \\
\hline Geriatrics & $1(2.2 \%)$ \\
\hline Internal medicine & $8(17.4 \%)$ \\
\hline Neurosurgery & $9(19.6 \%)$ \\
\hline Neurology & $8(17.4 \%)$ \\
\hline Nursing & $2(4.3 \%)$ \\
\hline Ophthalmology & $3(6.5 \%)$ \\
\hline Pathology & $1(2.2 \%)$ \\
\hline Psychiatry & $1(2.2 \%)$ \\
\hline Radiology & $10(21.7 \%)$ \\
\hline \multicolumn{2}{|l|}{ Legal jurisdiction } \\
\hline Settlement & $9(19.1 \%)$ \\
\hline Defendant verdict & $24(51.1 \%)$ \\
\hline Plaintiff verdict & $13(27.7 \%)$ \\
\hline Mixed verdict & $1(2.1 \%)$ \\
\hline Mean payout for plaintiff verdicts & $\$ 3,409,650.22$ \\
\hline Mean payout for settlements & $\$ 867,555.56$ \\
\hline
\end{tabular}

Values are presented as number (\%) of cases unless otherwise indicated.

* Some cases had more than 1 reason for litigation.

loss $(\mathrm{n}=12 ; 26 \%)$ and death $(\mathrm{n}=12 ; 26 \%)$ followed as the most common complaints leading to litigation following a procedure. Other outcomes included cranial nerve injury $(\mathrm{n}=8 ; 17 \%)$, emotional distress $(\mathrm{n}=7 ; 15 \%)$, stroke $(\mathrm{n}=$ $5 ; 11 \%)$, and speech impairment $(\mathrm{n}=5 ; 11 \%)$.

\section{Specialties of Defendants}

Of the 47 cases reviewed, a hospital, medical center, or healthcare system $(\mathrm{n}=19 ; 41.3 \%)$ was most commonly involved in medical malpractice disputes (see Table 1). Individual specialties that most often required defense due to malpractice claims were radiology $(n=10 ; 21.7 \%)$, neurosurgery $(n=9 ; 19.6 \%)$, neurology $(n=8 ; 17.4 \%)$, internal medicine $(n=8 ; 17.4 \%)$, and ophthalmology $(n=3 ; 6.5 \%)$. Family practice and nursing were also implicated, each with $2(4.3 \%)$ cases. According to our review of all cases, 
TABLE 2. Average payout based on medical specialty of the defendant

\begin{tabular}{lr}
\hline \multicolumn{1}{c}{ Specialties of Defendants } & Average Payout \\
\hline Anesthesiology & $\$ 400,000$ \\
\hline Cardiology & $\$ 950,000$ \\
\hline Endocrinology & $\$ 26,979,597$ \\
\hline Hospital, medical center, or healthcare system & $\$ 2,272,029$ \\
\hline Internal medicine & $\$ 997,500$ \\
\hline Neurology & $\$ 928,363$ \\
\hline Neurosurgery & $\$ 3,414,400$ \\
\hline Nursing & $\$ 50,000$ \\
\hline Ophthalmology & $\$ 183,333$ \\
\hline Pathology & $\$ 26,979,597$ \\
\hline Physiatry & $\$ 0$ \\
\hline Psychiatry & $\$ 1,830,000$ \\
\hline Radiology & $\$ 3,192,960$ \\
\hline
\end{tabular}

$6(12.8 \%)$ did not have an identifiable specialty involved in the case.

\section{Legal Jurisdiction, Verdict, and Payments}

A legal outcome occurring at the state level was documented for all 47 cases included in this study. The jury verdict was in favor of the defense in 24 (51.1\%) cases, while supporting the plaintiff in 13 (27.7\%) cases (Table 1). A settlement was reached in $9(19.1 \%)$ cases, while a mixed verdict was the result in only $1(2.1 \%)$ case. Payouts for all cases ranged from $\$ 100,00$ to $\$ 26,979,596.80$. The mean payout of verdicts in favor of the plaintiff was found to be $\$ 3,409,650.22$, while the mean payout for settle- ments was lower, at $\$ 867,555.56$ (see Table 1). Considering the groups and specialties with the greatest number of cases, the greatest average payout for specialties with $n \geq 3$ cases was in neurosurgery at $\$ 3,414,400$ (Table 2). The second highest average payout was in radiology at $\$ 3,192,960$. Ophthalmology held the lowest mean payout for specialties with $n \geq 3$ cases at $\$ 183,333$ (Fig. 1).

\section{Comparative Analysis}

We performed a univariate analysis of cases with a verdict in favor of the defendant and cases with a verdict in favor of the plaintiff. Cases with a verdict in favor of the plaintiff were more likely to be tried before a supreme court $(30.8 \%, \mathrm{n}=4$ vs 0$)$, while cases with a verdict in favor of the defendant were more likely to be tried before a superior court $(50.0 \%, \mathrm{n}=11$ vs $23.1 \%, \mathrm{n}=3$; overall $\mathrm{p}=$ 0.024 ) (Table 3). Moreover, cases with verdicts in favor of plaintiffs were more likely to involve an internal medicine physician $(38.5 \%, \mathrm{n}=5$ vs $4.2 \%, \mathrm{n}=1 ; \mathrm{p}=0.007)$.

\section{Discussion}

This descriptive study presents a 32-year analysis of medical malpractice litigation in the United States pertaining to the management of meningiomas. Looming fears of being charged with malpractice in conjunction with physician burnout and other stressors in the medical profession lead to a detrimental system where physicians and patients can unwittingly be placed at odds against one another in court. Litigious themes expanding through healthcare have created a rift between physicians and patients, causing financial concern to lead to more costly procedures, and overall stress, causing more medical errors.

In determining causative factors for litigation cases related to meningioma, demographic distribution and geog-

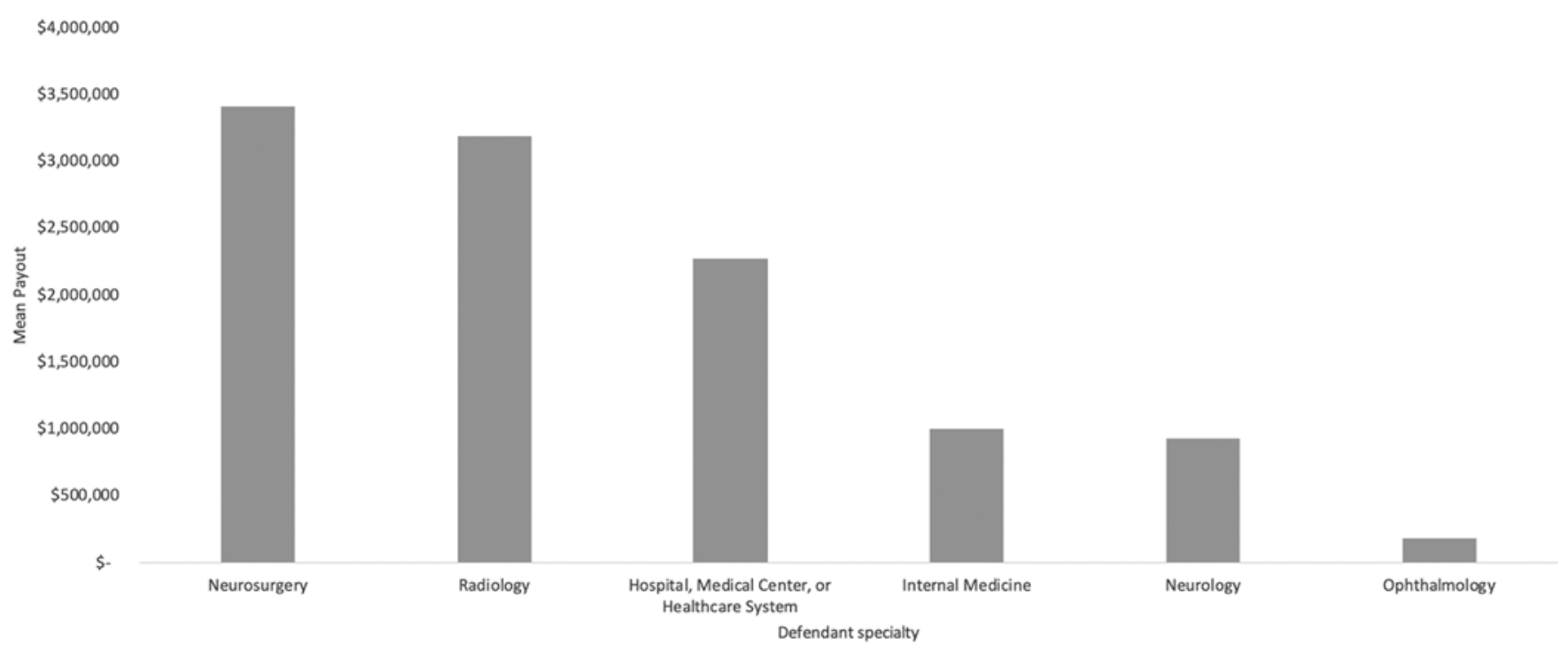

FIG. 1. Neurosurgery and radiology had the highest mean plaintiff payouts for defendant specialties $(n>2)$, with payouts of $\$ 3,414,400$ and $\$ 3,192,960$, respectively. Ophthalmology had the lowest mean payout at $\$ 183,333$. 
TABLE 3. Comparative analysis between cases with verdict in favor of defendant and those in favor of plaintiff

\begin{tabular}{|c|c|c|c|}
\hline & Defendant $(n=24)$ & Plaintiff $(n=13)$ & p Value \\
\hline Sex & & & 0.052 \\
\hline Female & $12(52.2 \%)$ & $11(84.6 \%)$ & \\
\hline Male & $11(47.8 \%)$ & $2(15.4 \%)$ & \\
\hline Patient age in yrs & & & 0.133 \\
\hline Mean \pm SD & $57.533 \pm 12.597$ & $47.857 \pm 15.421$ & \\
\hline Range & $42-82$ & $29-70$ & \\
\hline Type of court & & & 0.024 \\
\hline Circuit & $6(27.3 \%)$ & $3(23.1 \%)$ & \\
\hline $\begin{array}{l}\text { Court of Common } \\
\text { Pleas }\end{array}$ & $0(0.0 \%)$ & $2(15.4 \%)$ & \\
\hline District & $4(18.2 \%)$ & $1(7.7 \%)$ & \\
\hline Superior & $11(50.0 \%)$ & $3(23.1 \%)$ & \\
\hline Supreme & $0(0.0 \%)$ & $4(30.8 \%)$ & \\
\hline $\begin{array}{l}\text { Unknown state } \\
\text { court }\end{array}$ & $1(4.5 \%)$ & $0(0.0 \%)$ & \\
\hline State & & & 0.360 \\
\hline Arizona & $1(4.2 \%)$ & $0(0.0 \%)$ & \\
\hline California & $6(25.0 \%)$ & $2(15.4 \%)$ & \\
\hline Colorado & $1(4.2 \%)$ & $0(0.0 \%)$ & \\
\hline Florida & $1(4.2 \%)$ & $0(0.0 \%)$ & \\
\hline Illinois & $1(4.2 \%)$ & $2(15.4 \%)$ & \\
\hline Indiana & $2(8.3 \%)$ & $0(0.0 \%)$ & \\
\hline Massachusetts & $1(4.2 \%)$ & $1(7.7 \%)$ & \\
\hline Michigan & $2(8.3 \%)$ & $0(0.0 \%)$ & \\
\hline Missouri & $1(4.2 \%)$ & $0(0.0 \%)$ & \\
\hline New Jersey & $1(4.2 \%)$ & $0(0.0 \%)$ & \\
\hline New York & $1(4.2 \%)$ & $4(30.8 \%)$ & \\
\hline Oregon & $1(4.2 \%)$ & $1(7.7 \%)$ & \\
\hline Pennsylvania & $0(0.0 \%)$ & $2(15.4 \%)$ & \\
\hline Texas & $1(4.2 \%)$ & $1(7.7 \%)$ & \\
\hline Utah & $1(4.2 \%)$ & $0(0.0 \%)$ & \\
\hline Washington & $2(8.3 \%)$ & $0(0.0 \%)$ & \\
\hline Wisconsin & $1(4.2 \%)$ & $0(0.0 \%)$ & \\
\hline Type of institution & & & 0.493 \\
\hline Academic & $2(18.2 \%)$ & $2(22.2 \%)$ & \\
\hline Private & $9(81.8 \%)$ & $6(66.7 \%)$ & \\
\hline Public & $0(0.0 \%)$ & $1(11.1 \%)$ & \\
\hline Defendant's position & & & 0.710 \\
\hline Multiple & $3(13.0 \%)$ & $3(23.1 \%)$ & \\
\hline Physician & $20(87.9 \%)$ & $10(76.9 \%)$ & \\
\hline $\begin{array}{l}\text { Malpractice vs } \\
\text { negligence }\end{array}$ & & & 0.653 \\
\hline Malpractice & $21(87.5 \%)$ & $12(92.3 \%)$ & \\
\hline Negligence & $3(12.5 \%)$ & $1(7.7 \%)$ & \\
\hline \multicolumn{4}{|l|}{ Physician type } \\
\hline Family practice & $2(8.3 \%)$ & $0(0.0 \%)$ & 0.285 \\
\hline Geriatrics & $1(4.2 \%)$ & $0(0.0 \%)$ & 0.456 \\
\hline Internal medicine & $1(4.2 \%)$ & $5(38.5 \%)$ & 0.007 \\
\hline
\end{tabular}

CONTINUED IN NEXT COLUMN
» CONTINUED FROM PREVIOUS COLUMN

TABLE 3. Comparative analysis between cases with verdict in favor of defendant and those in favor of plaintiff

Defendant $(n=24) \quad$ Plaintiff $(n=13) \quad p$ Value

\begin{tabular}{lccc}
$\begin{array}{l}\text { Physician type } \\
\text { (continued) }\end{array}$ & & \\
\hline \multicolumn{1}{l}{ Radiology } & $7(29.2 \%)$ & $3(23.1 \%)$ & 0.690 \\
\hline Physiatry & $2(8.3 \%)$ & $0(0.0 \%)$ & 0.285 \\
\hline $\begin{array}{l}\text { Ophthalmology } \\
\text { Neurosurgery }\end{array}$ & $2(8.3 \%)$ & $1(7.7 \%)$ & 0.946 \\
\hline Neurology & $6(25.0 \%)$ & $1(7.7 \%)$ & 0.199 \\
\hline $\begin{array}{l}\text { Hospital or health } \\
\text { care system }\end{array}$ & $7(29.2 \%)$ & $7(53.8 \%)$ & 0.139 \\
\hline Litigation category & $2(8.3 \%)$ & $1(7.7 \%)$ & 0.946 \\
\hline $\begin{array}{l}\text { Failure to consent } \\
\text { Failure to diagnose }\end{array}$ & $16(66.7 \%)$ & $12(92.3 \%)$ & 0.083 \\
\hline $\begin{array}{l}\text { Poor follow-up } \\
\text { Surgical } \\
\text { complication }\end{array}$ & $3(12.5 \%)$ & $0(0.0 \%)$ & 0.184 \\
\hline $\begin{array}{l}\text { Failure to treat } \\
\text { S }\end{array}$ & $3(16.7 \%)$ & $2(15.4 \%)$ & 0.920 \\
\hline
\end{tabular}

Values are presented as number (\%) of cases unless otherwise indicated.

raphy were not found to be necessarily impactful. A clear explanation for the greatest number of cases being present in California $(\mathrm{n}=12 ; 25.5 \%)$ and New York $(\mathrm{n}=6$; $12.8 \%$ ) cannot entirely be elucidated, but the large populations in these states in comparison to other states may be a reason (Table 1). California's population, the largest in the United States, is estimated to be approximately 39.5 million, while the fourth largest state, New York, has an estimated population of 19.5 million. ${ }^{11}$ Interestingly, states with the second and third greatest populations, which are Texas and Florida, respectively, only had 2 (4.3\%) cases each (see Table 1). Regional variation noted here likely has to do with laws regarding malpractice in these states. The Northeast is considered to be generally a typically more litigious region, with a lower percentage of states that implemented tort reform. ${ }^{12}$ Unlike New York, the states of Texas and Florida choose to limit noneconomic damages awarded due to claims.

In this study, the most common reasons for allegations of malpractice were failure to diagnose $(n=32 ; 68.1 \%)$, surgical complications $(\mathrm{n}=9 ; 19.1 \%)$, and negligent follow-up care $(\mathrm{n}=5 ; 10.6 \%)$ (Table 1$)$. These findings are consistent with data presented by a recent nationwide survey of medical doctors regarding malpractice reports, conducted in 2017. Data collected in the 2017 survey show that the top 4 reasons for a medical lawsuit were the following: failure to diagnose (31\%), complications from treatment or surgery (27\%), poor outcome or disease progression (24\%), and failure to treat or delayed treatment $(17 \%){ }^{13}$

Meningiomas are the most common primary tumor of the central nervous system diagnosed in the United States and are often asymptomatic. Clinical presentation is dependent on the location of the tumor, but symptoms are 


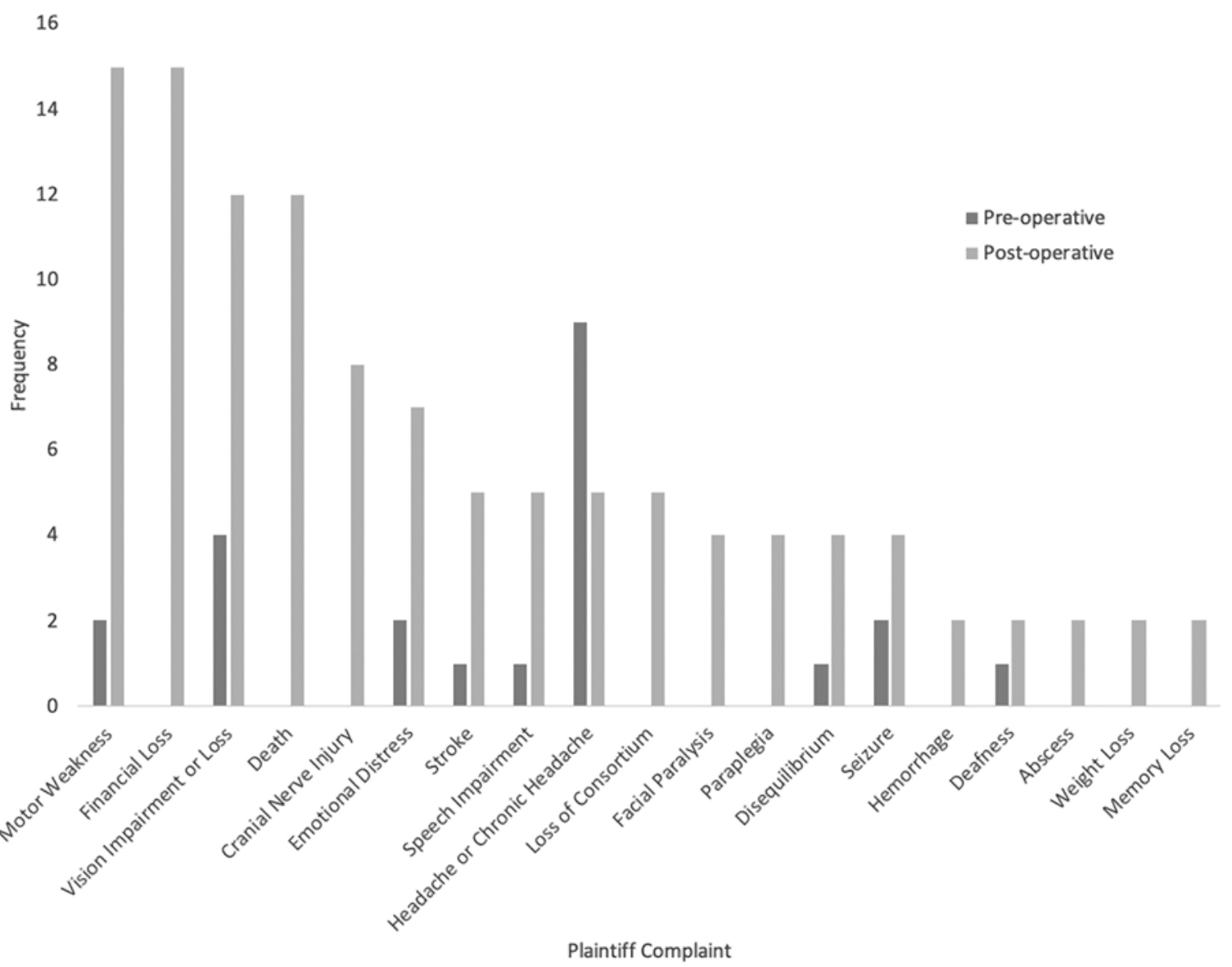

FIG. 2. The most frequent preoperative plaintiff complaints were headache or chronic headache $(n=9 ; 20 \%)$ and vision impairment or loss $(n=4 ; 9 \%)$. The most frequent postoperative complaints were motor weakness $(n=15 ; 33 \%)$ and financial loss $(n=$ $15 ; 33 \%)$, followed by visual impairment or loss $(n=12 ; 26 \%)$ and death $(n=12 ; 26 \%)$.

often insidious and include headache due to increased intracranial pressure or dural irritation, focal deficits such as weakness, or seizures induced by mass effect. ${ }^{9}$ The expectation of the aforementioned symptoms to occur most frequently is supported in our study, with the most common preoperative complaints found to be headache $(\mathrm{n}=9 ; 20 \%)$ and visual impairment or loss $(n=4 ; 9 \%)$ (Fig. 2). The differential diagnosis for these symptoms is broad and can occur as an initial presentation for a range of disorders. This constellation of varied onset, symptom severity, and clinician specialty performing the workup and evaluation may in part provide reasoning for the frequency of plaintiffs claiming that there was a failure to diagnose. Claims like this are well represented in our data set, as several specialties were implicated in litigation. The two specialties most involved in claims were radiology $(\mathrm{n}=10 ; 21.7 \%)$ and neurosurgery $(\mathrm{n}=9 ; 19.6 \%)$. These fields encompass arguably the most critical components of care involved in the treatment of meningiomas, which are timely diagnosis and application of appropriate treatment options or indications, as well as surgical outcomes. The importance of providing timely diagnosis and care also speaks to the concept of continuity of care. While multiple specialties are traditionally involved in the workup of patients with meningiomas, there needs to be a "captain of the ship," an individual or specialty that is primarily responsible for patient follow-up and updates. While this individual or specialty may change depending on who is initiating the workup or primarily managing the patient's care, the lack of communication between care providers among each other and with the patient can readily lead to failure to diagnose, failure to treat, delayed treatment, and subsequent disease progression, all implicated as causes for litigation.

With the advent of widespread high-quality imaging being more readily available, an increasing number of intracranial meningiomas are being diagnosed incidentally. ${ }^{14}$ Although most meningiomas are treated nonoperatively, the location of the lesions requiring surgical intervention may determine the risk of intraoperative or postoperative complication such as intracranial hemorrhage, cerebral artery occlusion, and venous thromboembolism. ${ }^{15-17}$ The treatment option selected for a given meningioma diagnosis has a profound impact on patient outcome and the associated healthcare costs. ${ }^{15}$ Of the many postoperative symptoms or complaints documented in our study, motor weakness $(\mathrm{n}=15 ; 33 \%)$ and financial losses $(\mathrm{n}=15 ; 33 \%)$ were the most numerous. An inherent limitation of this national database study with use of the Westlaw database 
is the absence of medical information on intraoperative and postoperative complications. However, information on postoperative symptoms, such as motor weakness, visual impairment, speech impairment, and seizure, was elicited and gathered. The severity of possible postoperative complications emphasizes the importance of ensuring that patients understand their prognosis and expected convalescence when discussing the diagnosis or, in particular, the associated risks of any surgical approach to treatment. A detailed and clear informed discussion of the potential complications and surgical interventions, both temporary and permanent, is mandatory. To be adequate, this communication may require the participation of family or caretakers as well. Among patients who experience any range of medical injuries following surgery, patients who have been provided with adequate knowledge prior to surgery and have participated in a clear informed consent discussion that included their families may be less likely to submit a malpractice claim.

Neurosurgical procedures often involve considerable morbidity that can prove costly for both healthcare systems and patients. ${ }^{18}$ The number of patients claiming financial loss highlights the economic burden faced by persons undergoing surgical procedures with high risk and requisite follow-up care. Clinical risk factors and characteristics are useful tools in assessing the likelihood of patient postoperative complication or readmission. ${ }^{19}$ With varying laws by state and a multitude of specialties implicated in litigation in the treatment of meningiomas, one constant is the need for a detailed and very clear informed consent discussion. In addition, an in-depth discussion of treatment options and goals of care with the patient and their family is essential before proceeding with any intervention.

Previously cited literature of medical malpractice suits using the Westlaw database outlined several limitations to its analysis. One limitation of our study, specifically, is the sample size. This limited sample size could be due to a lack of comprehensive search terms entered into the database. We limited our search to cases containing the word "meningioma." However, it is possible that this keyword was not all-inclusive and therefore some meningioma cases may have been missed.

Additionally, the Westlaw database itself is limited in its scope of malpractice cases. Westlaw does not include those claims that are mediated outside the scope of the judicial system or cases that were dropped before formal registration. ${ }^{20}$

\section{Conclusions}

Our study presents a 32-year analysis of meningiomarelated medical malpractice suits in the United States. Over one-half of the cases resulted in a defendant's verdict, with failure to diagnose cited as the most common reason for litigation. Radiology and neurosurgery were listed as the most common physician specialties for defendants, and these specialties also involved some of the largest average payouts based on specialty (for specialties with $\geq 3$ occurrences). Cases with a verdict in favor of the plaintiff were more likely to involve an internal medicine physician as the defendant.
It is our hope that the information presented here serves to increase neurosurgeons' awareness of the multitude of factors that are associated with medical malpractice litigation and are also unfavorable with regard to the treatment of patients with a meningioma. This knowledge can be utilized to practice good risk management, discourage costly positive assurance behaviors, minimize the probability of litigation, and improve patients' and physicians' overall well-being.

\section{References}

1. Jena AB, Seabury S, Lakdawalla D, Chandra A. Malpractice risk according to physician specialty. N Engl J Med. 2011; 365(7):629-636.

2. Attenello FJ, Buchanan IA, Wen T, et al. Factors associated with burnout among US neurosurgery residents: a nationwide survey. J Neurosurg. 2018;129(5):1349-1363.

3. Motluk A. Do doctors experiencing burnout make more errors? CMAJ. 2018;190(40):E1216-E1217.

4. Mello MM, Chandra A, Gawande AA, Studdert DM. National costs of the medical liability system. Health Aff (Millwood). 2010;29(9):1569-1577.

5. Reisch LM, Carney PA, Oster NV, et al. Medical malpractice concerns and defensive medicine: a nationwide survey of breast pathologists. Am J Clin Pathol. 2015;144(6):916-922.

6. Antoci A, Fiori Maccioni A, Russu P. The ecology of defensive medicine and malpractice litigation. PLoS One. 2016; 11(3): 0150523.

7. Rovit RL, Simon AS, Drew J, et al. Neurosurgical experience with malpractice litigation: an analysis of closed claims against neurosurgeons in New York State, 1999 through 2003. J Neurosurg. 2007;106(6):1108-1114.

8. Kessler RA, Benzil DL, Loewenstern J, et al. Malpractice litigation in brain tumor surgery: a 31-year analysis of causative factors in the United States from the Westlaw database. World Neurosurg. 2019;122:e1570-e1577.

9. Buerki RA, Horbinski CM, Kruser T, et al. An overview of meningiomas. Future Oncol. 2018;14(21):2161-2177.

10. Grauberger J, Kerezoudis P, Choudhry AJ, et al. Allegations of failure to obtain informed consent in spinal surgery medical malpractice claims. JAMA Surg. 2017;152(6): e170544.

11. North Carolina becomes ninth state with 10 million population. US Census Bureau. December 22, 2015. Accessed September 14, 2020. https://www.census.gov/ newsroom/press-releases/2015/cb15-215.htm

12. Deng Y, Zanjani G. What drives tort reform legislation? An analysis of state decisions to restrict liability torts. J Risk Insur. 2018;85(4):959-991.

13. Levy S, Kane L. Medscape Malpractice Report 2017. November 15, 2017. Accessed September 14, 2020. https: //www.medscape.com/slideshow/2017-malpracticereport-6009206\#1

14. Baldi I, Engelhardt J, Bonnet C, et al. Epidemiology of meningiomas. Neurochirurgie. 2018;64(1):5-14.

15. Karhade AV, Fandino L, Gupta S, et al. Impact of operative length on post-operative complications in meningioma surgery: a NSQIP analysis. J Neurooncol. 2017;131(1):59-67.

16. Connolly ID, Cole T, Veeravagu A, et al. Craniotomy for resection of meningioma: an age-stratified analysis of the MarketScan longitudinal database. World Neurosurg. 2015;84(6): 1864-1870.

17. Haber MA, Abd-El-Barr M, Gormley W, et al. Neurosurgical complications: what the radiologist needs to know. Emerg Radiol. 2019;26(3):331-340.

18. De la Garza Ramos R, Goodwin CR, Nakhla J, et al. The nationwide burden of neurological conditions requiring emergency neurosurgery. Neurosurgery. 2017;81(3):422-431. 
19. Lopez Ramos C, Brandel MG, Rennert RC, et al. Clinical risk factors and postoperative complications associated with unplanned hospital readmissions after cranial neurosurgery. World Neurosurg. 2018;119:e294-e300.

20. Thomas R, Gupta R, Griessenauer CJ, et al. Medical malpractice in neurosurgery: a comprehensive analysis. World Neurosurg. 2018;110:e552-e559.

\section{Disclosures}

The authors report no conflict of interest concerning the materials or methods used in this study or the findings specified in this paper.

\section{Author Contributions}

Conception and design: Agarwal, Boyke, Bader. Acquisition of data: Agarwal, Boyke, Bader, Naidu, Lam, Alvi. Analysis and interpretation of data: all authors. Drafting the article: all authors. Critically revising the article: Agarwal, Boyke, Bader, Naidu, Lam, Alvi. Reviewed submitted version of manuscript: Agarwal, Boyke, Bader, Naidu, Alvi. Approved the final version of the manuscript on behalf of all authors: Agarwal. Statistical analysis: Agarwal, Boyke, Bader. Administrative/technical/material support: Agarwal, Boyke. Study supervision: Agarwal, Boyke.

\section{Correspondence}

Vijay Agarwal: Montefiore Medical Center, The University Hospital for the Albert Einstein College of Medicine, Bronx, NY. vjagarwal@gmail.com. 